\title{
UNA TECNICA PARA PREPARACIONES PERMANENTES DE LEVADURAS
}

ziabras clave:Preparaciones permanentes, levaduras

Te words: Permanent slides, yeasts.

\section{RESUMEN}

Modificando una técnica indicada por Artagaveitía-Allende para microcultivos de levaduras, se obtuvieron entre lamina y laminilla, preparaciones teñidas permanentes que mantienen su integridad por largo tiempo.

\section{RODUCCION:}

Entre los métodos de microcultivos utilizados para la observación de estructuras de hongos y las posteriores preparaciones permanentes en láminas, pueden citarse entre otros, los de gota pendiente (Vantieghem \& Le Mounier ${ }^{5}$ ), la inmersión de la lámina en medio sólido licuado (Rivalier \& Lydei ${ }^{5,8}$ y Rivalier \& Seydel modificado por Langeron \& Guerra ${ }^{5}$ con fragmento de medio sólido sobre la lámina (Ridel ${ }^{4}$ ) y el medio licuado de (Porto et $\mathrm{al}^{4}$ ). Algunos textos describen el método Riedel ${ }^{2,7}$ o el de Rivalier \& Sey$\operatorname{del}^{3,6}$, sin citar los respectivos nombres de los autores, lo que sugiere una falsa idea de que son métodos dife.rentes

En estos métodos, el calentamiento del sistema medio/cultivo, favorece la deshidratación y desecación, y antecede a la fijación y coloración. A pesar de estar bien descritos, ninguno de éstos son prácticos y adecuados para preparaciónes permanentes con levaduras.

La técnica de Dalmau ${ }^{3,6}$, es indicada para microcultivo de levaduras, desarrolladas directamente en

\section{Maria Francisca Simas Teixeira* Lucilaide Oliveira Santos* Lucinete Aciole de Queiroz*** Sonia María da Silva de Carvalho*}

* Lab.de Micología, Dep. de Patología, Inst. de Ciencias Biológicas,Universidade do Amazonas, Estrada do Contorno, s/n. CEP.69000,Manaos, Amazonas, Brasil. ** Dep. de Micología do Centro de Ciencias Biológicas, Universidade Federal de Pernambuco,Av. Prof .Artur de Sá, s/n, Cidade Universitária, Recife, PE.Brasil.

SUMMARY

[A technique for permanents slides of yeasts]

This paper presents the microculture of yeast according to the modified technique of Artagaveitia- Allende. In this method, the fungal structure are stained and remains intire for permanent slides.

la superficie del medio sólido en placa; la utilizada por Artagaveitía-Allende ${ }^{1}$ (comunicación personal, 1969), consta del microcultivo de levaduras en el medio sólido fundido y distribuído con pipeta sobre una parte de la lámina, sin posterior fraccionamiento del sistema medio/ cultivo (difiere también del método de Porto et al. ${ }^{4}$ ). En ambas técriicas, no se indica la subsiguiente preparación permanente de la lámina.

Por lo expuesto, este trabajo tiene como objetivos: Aplicar la técnica indicada por este autor para microcultivos de levaduras con el fin de obtener posteriores preparaciones permanentes.

\section{MATERIAL Y METODOS}

Se emplearon 40 cepas de levaduras para los microcultivos, según la técnica indicada por Artagaveitía-Allende, ${ }^{1}$ usando agar Corn Meal, ${ }^{3,6}$ y azul de Amann. ${ }^{4}$

Microcultivos. Se colocó un portaobjeto sobre otro, dispuesto en cruz, o sobre un tubo fino de vidrio recurvado en forma de $U$ (como soporte), en el interior 
de una placa de Petri, con fondo revestido con papel filtro u otro tipo de papel absorbente. Se esterilizó en autoclave,para evitar la ruptura del portaobjetos.

En baño-maría, se licúa el agar Corn-Meal y con pipeta graduada estéril se extienden $1-2 \mathrm{ml}$ sobre la lámina, en una capa uniforme del medio, sin dejar que el mismo alcance los márgenes de éstos.

Después de la solidificación del medio, se sembró en su superficie la levadura en una estría central longitudinal, teniendo el cuidado de no perforarlo.

Con el auxilio de una pinza flameada y enfriada, se cubrió parcialmente con un cubreobjeto una parte (la mitad aproximadamente en sentido longitudinal) de la estría del inóculum, dejando la otra en total aerobiosis. Con auxilio de una pipeta esterilizada, se humedecío con agua estéril el papel colocado en el fondo de la placa, para mantener la humedad ambiente y evitar la deshidratación del medio de cultivo.

Todas las placas se dejaron a $\mathrm{T}^{\circ}$ ambiente (27$30^{\circ} \mathrm{C}$ ), durante 72 horas.

Observación microscópica. Para evitar la condensación en los objetivos, se cubrió con un cubreobjeto estéril la parte de la estría correspondiente al desarrollo en aerobiosis. Sin colorantes se efectuó la observación microscópica en los 2 sistemas de desarrollo: el de microaerobiosis (con el primer cubreobjeto) y el de aerobiosis (con el segundo cubreobjeto) (Figura 1).

Coloración. Se colocaron gotas de azul de Amann alrededor de los cubreobjetos, sin que estos fueran cubiertos por el colorante.

Preparación de láminas permanentes:

a) Deshidratación. Se retiró de la placa el portaobjetos con los microcultivos junto al soporte y el papel humedecido del fondo de ésta; ésta se secó con papel estéril y se procedió a colocar en ella el portaobjeto con el microcultivo, y al mismo tiempo, en la cara interna de la tapa, un disco de papel absorvente para evitar que el agua de condensación humedeciera el microcultivo. Al mismo tiempo se mantuvo la humedad necesaria evitando así la deshidratación brusca del medio. Se incubó a $37^{\circ} \mathrm{C}$ hasta completar la deshidratación, la cual fué gradual y prolongada durante un período de hasta 8 días.

b) Recubrimiento.- Después de retirar el exceso del medio teñido con colorante alrededor de las laminillas, se sellaron sus bordes con esmalte para unas o bálsamo de Canadá para su observación al micros- copio para luego archivarse en la elasmoteca.

\section{RESULTADOS Y DISCUSION:}

Blastosporas, clamidosporas, artrosporas, pseudomicelio y micelio verdadero, son fácilmente observados aunque sea sin coloracion. Cuando son coloreadas con azul de $A m a n n^{4,7}$, éstas estructuras son visualizadas en azul, lo mismo ocurre en relación al clivaje citoplasmático (endosporas), como así los ascos y ascosporas de las levaduras.

La deshidratación gradualy prolongada a $37^{\circ} \mathrm{C}$ del microcultivo teñido, permite la preparación permanente de láminas con levaduras, sin producir modificaciones en el ordenamiento y en la forma de las estructuras.

Las preparaciones permanentes, obtenidas a través de esta técnica, están archivadas en la elasmoteca del Laboratorio de Micología, Departamento de Patología, Universidad de Amazonas. Entre estas preparaciones permanentes, muchas están archivadas hace 4 años y continúan estabilizadas en cuanto a ordenación, forma y color de sus estructuras. Lo expuesto, indica que éste es un método práctico y adecuado para preparaciones permanentes de estos microorganismos. 


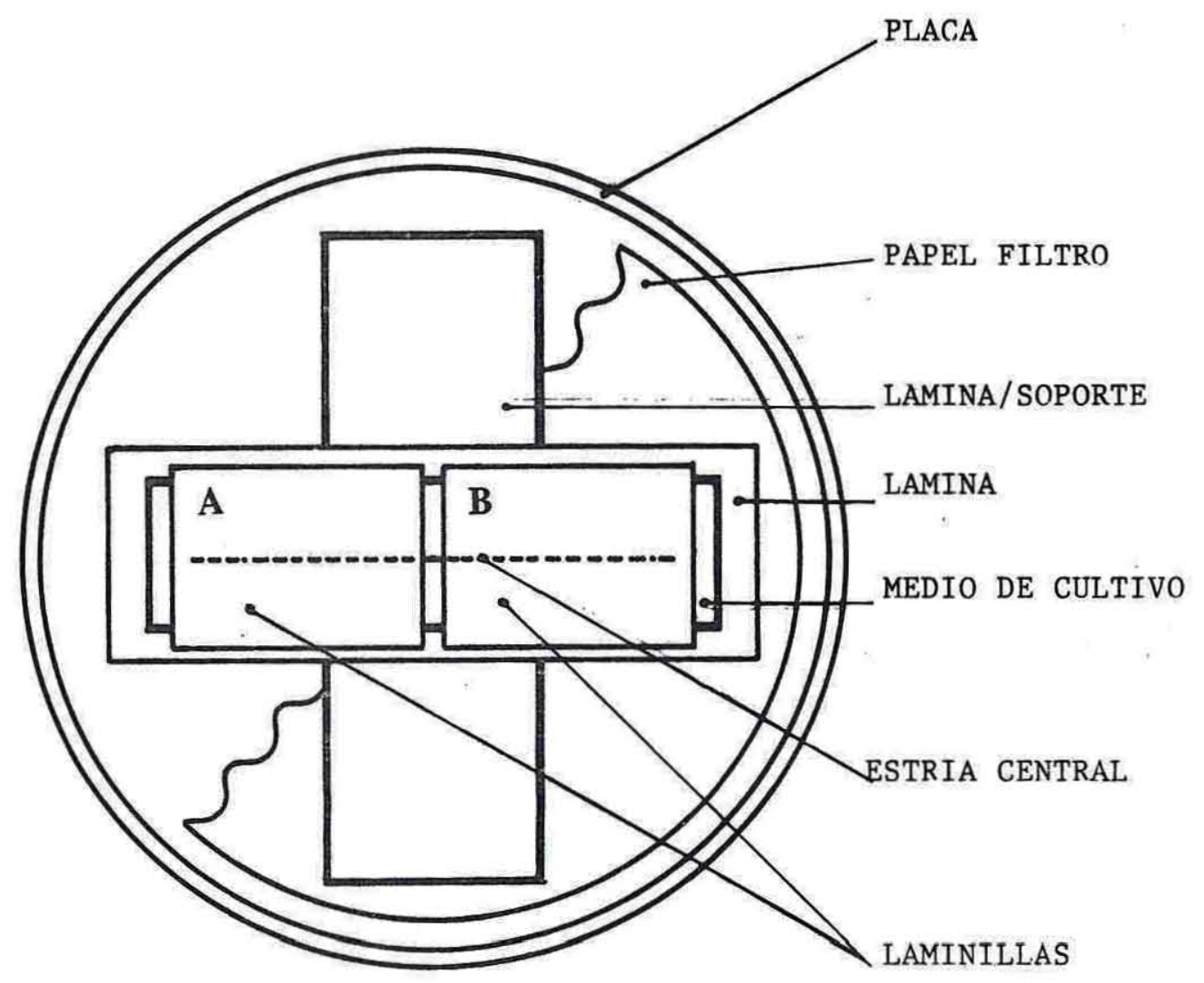

FIGURA 1 - MICROCULTIVO

Laminilla A: Colocada sobre la estría después de efectuada la siembra Laminilla B: Colocada sobre la estría 72 horas después del desarrollo de microcultivo.

\section{REFERENCIAS}

1.- Artagaveitía-Allende R. C. (1968) Apostila. Levaduras: Caracteres generales. Clasificación. Mciabolismo. Aislamiento. Identificación. Levaduras osmofílicas. Apostila, Lab. de Micologia, Cátedra de Microbiología, Facultad de Química, Montevideo, 19p.

2- Hawsworth, D.L. (1974) Mycologist' \& Handtrook. C.A.B., 231 p. 3.- Kreger-van, R. N. J. W. (1984). The yeasts. A taxonomic study. $3^{\circ} \mathrm{ed}$. Elsevier Sci. Publi. Amsterdam $1051 \mathrm{p}$.

4. Lacaz, C. S.; Orto, E; Martins, J. E. C. (1984). Micología Médica. Fungos, actinomicetes e algas de interesse médico. $7^{\circ}$ ed., Sao Paulo, Sarvier- EDUSP, 479 p.
5.- Langeron, M.; Vanbreuseghem, R. (1952). Prècis de Mycologie. Mycologgie Gènèrale. Mycologie humaine et animale. Techniques. Masson et Cie. Editeurs, Paris, 703 p.

G.- Lodder, R. J. (1974). The Yeasts. A taxonomic study. Oxford, North Holland Publishing Company, $1385 \mathrm{p}$

7.- Stevens, R. B. (1974). Mycology Guidebook. University of Washington Press, 703 p.

8.-Vanbreuseginem, R. (1966). Guide practique de mycologie mèdicale et veterinaire. Masson et Cle.,Editeurs, Paris, 206 p. 